DOI: $10.20472 / S S .2019 .8 .1 .003$

\title{
LOCALIZING DISASTER RISK REDUCTION
}

\section{LILYBETH MATUNHAY, JONEL MILAN, CECILIO PAQUEO}

\begin{abstract}
:
Creation of awareness among people living in disaster-prone areas of the imminent risk they face and how best to respond when it occurs can be done through a broad range of avenues to enhance local people's confidence and empower them to act when faced with adversity. This enables and fosters increased participation among the local community to tackle the effects of the disaster. This study focused in determining the level of performance in the implementation of the programs of the Barangay Disaster Risk Reduction and Management Committee (BDRRMC) in Barangay San Miguel, Compostela, Compostela Valle, Philippines for C.Y. 2015. The Community has been awarded as the Best Implementer in disaster risk reduction management in CY 2015. The result captures the interest of the researchers to substantiate the result from the community. This is a descriptive survey method utilizing a survey questionnaire administered to randomly selected respondents from the barangay. The result reveals that there was a high level of performance of the BDRRMC in the implementation of the disaster risk reduction management plan due to the sustained efforts of the local officials and the community residents. It is recommended that such 'disaster preparedness' culture should be continued through regular and strict monitoring in the implementation of the DRRM plan and initiate more efforts relating to disaster preparedness contingency plans and measures.
\end{abstract}

\section{Keywords:}

disaster risk reduction, barangay disaster risk reduction council, performance, disaster culture, local $\&$ community level

JEL Classification: Q01, Q54, Q58

\section{Authors:}

LILYBETH MATUNHAY, Comp0stela Valley State College, Philippines, Email: lilybethmatunhay@gmail.com JONEL MILAN, University of Southeastern Philippines-Compostela Center, Philippines, Email: lilybethmatunhay@gmail.com CECILIO PAQUEO, Local Government Unit of Compostela, Philippines, Email: lilybethmatunhay@gmail.com

\section{Citation:}

LILYBETH MATUNHAY, JONEL MILAN, CECILIO PAQUEO (2019). Localizing Disaster Risk Reduction. International Journal of Social Sciences, Vol. VIII(1), pp. 31-42., 10.20472/SS.2019.8.1.003 


\section{Introduction}

Disasters have an enormous impact on human development. Globally, events such as earthquakes, floods and droughts contribute to tens of thousands of deaths, hundreds of thousands of injuries, and billions of dollars in economic losses each year (Adewale, 2012). In developing countries, disasters represent a major source of risk for the poor and can potentially destroy development gains and accumulated wealth. This has been recognized by the UN Member States in the Millennium Declaration, which sees the mounting losses caused by disasters as a major threat towards meeting the Millennium Development Goals (Dilley, 2005). The Asia Pacific region is the most disaster prone and most disaster affected in the world (Chaisatit, Hernández, Rodríguez, \& Campos, 2014) (Matunhay L. , 2018).

In the Philippines, in line with the climate change issue that affects the country, there has been a high need for data in aid of developing a disaster management program as mandated by Republic Act 10121 (Matunhay L. M., 2018). The current national disaster response approach adopted by the Philippine government is two-tiered. At the national government level, response is tailored to augment operations at the local level when local government units (LGUs) are still able to carry out their mandate [6]. An analysis of the impacts of natural disasters on the natural resources and environment of the Philippines will help bring further to light the nature and extent of these effects. For an economy largely dependent on agriculture and its natural resources and environment, the data and information as well as overall knowledge gained from the study may prove useful in developing strategies to address the illeffects of natural disasters. Moreover, the results and findings may assist in identifying new studies that can soon be undertaken in relation to natural disasters which are community-based.

Management of disaster principally starts at the level of the local government, owing to the decentralized system embedded in the Local Government Code of 1991 (Republic Act 7160). LGUs are deemed as "first disaster responders". The continuous distraction of rural livelihoods activities, loss of lives and displacements of large numbers of rural populations (Malayang III, 2013) has brought about questioning the applicability of risk and disaster mitigation and management approach implementation in the Philippines.

In Compostela Valley, Barangay San Miguel established Barangay Disaster Risk Reduction and Management Committee (BDRRMC) in 2013. Two years later, the BDRRMC became a recipient of an award as Best Implementer by the Department of Interior and Local Government Unit which manifests that the community advocates the importance of participatory governance where the response of the barangay is the key to coping and adapting to change. Hence, this captures the interest of the researchers to determine the level of performance of the community in terms of disaster risk reduction management.

\subsection{Objective of the Study and Problem Statement}

The intent of the study is to determine the level of performance of the Barangay Disaster Risk Reduction and Management Committee in the implementation of the programs for C.Y. 2015 in Barangay San Miguel, Compostela, Compostela Valley 
Specifically, this sought to find answers to this question: What is the level of performance of the BDRRMC in Barangay San Miguel in the implementation of disaster risk and reduction programs in terms of preparation, mitigation, response and recovery?

\subsection{Theoretical and Conceptual Frameworks}

The principles and concepts that have helped shape the framework of this study are mainly drawn from the structural- functionalist theory, the Hyogo Framework for Action (Hyogo Framework for Action 2005-2015: Building the resilience of nations and communities to disasters, 2005) , the Philippine Disaster Risk Reduction and Management Act of 2010 (R.A. 10121), the National Disaster Risk Reduction and Management Framework of the Philippines, and the National Disaster Risk Reduction and Management Plan, 2011 to 2028 (Matunhay L. , 2018).

Meanwhile, Figure 1 illustrates the relationship of variables in the study. The independent variables are preparation, mitigation, response and recovery while the dependent variable is the level of performance of Barangay Disaster Risk Reduction and Management Committee (BDRRMC) in Barangay San Miguel on the implementation of programs for C.Y. 2015.

\section{Figure 1: Schematic Diagram of the Study}

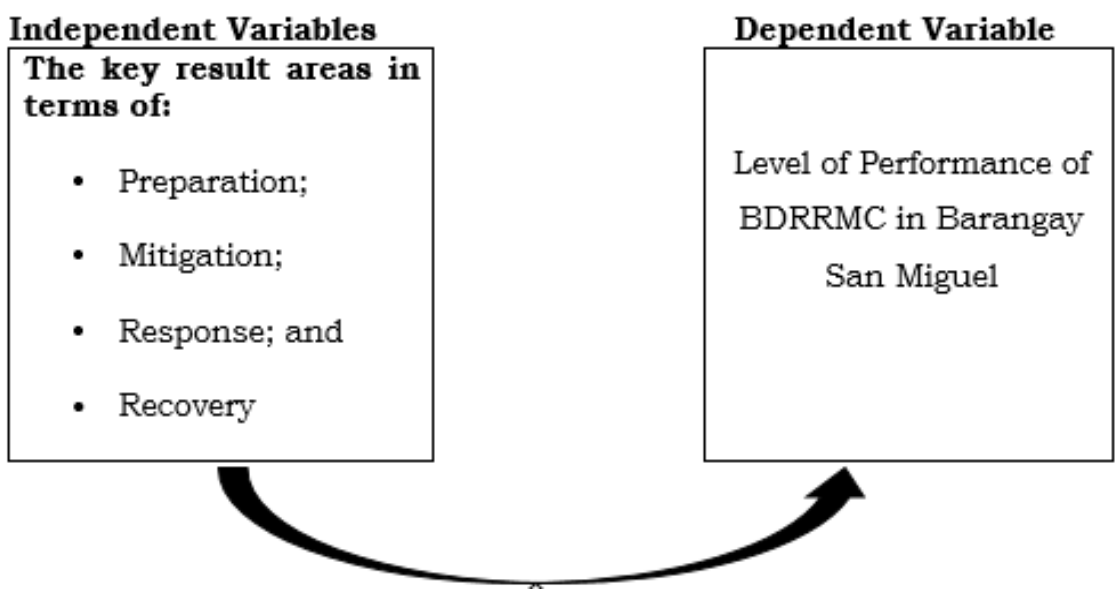

\section{Methodology}

The study used Descriptive Survey Method. Survey questionnaire administered to the respondents was the primary source of data.

\subsection{Sampling Technique}

Slouvin Formula was used to get the random samples. Stratified Random Sampling was utilized to get representation from every section of the community.

\subsection{Treatment of Data}


Average Weighted Mean was used to determine the level of performance of the BDRRMC on the identified variables. The level of performance of BDRRMC was measured using the five point Likert scale with the corresponding descriptive equivalent as follows:

$\begin{array}{cl}\text { Scale } & \text { Descriptive equivalent } \\ 5 & \text { Excellent } \\ 4 & \text { Very Good } \\ 3 & \text { Average } \\ 2 & \text { Good } \\ 1 & \text { Poor }\end{array}$

\section{Results and Discussions}

3.1 Level of performance of BDRRMC in Barangay San Miguel on the implementation of programs for C.Y. 2015.

Table 1 shows the level of performance of BDRRMC in terms of disaster preparation. With an excellent descriptive remarks, the preparation for contingency plans with local risk map, and its rehearsal and dissemination is effectively contained by the barangay. Further, the conduct of drills to find the effectiveness of contingency plans ; the display of disaster-related signage, markers and directional signs in strategic locations obtained with an establishment of early warning system to alarm the residents when disaster strikes indicated a total percentage of 4.73 with a descriptive equivalent of excellent, which means the performance is outstanding.

The readiness of BDRRMC effectively mitigated the effects of the disaster that occurred in their locality. Besides, they have appropriately acquired necessary skills and equipage that made residents ready for whatever catastrophic events that may strike the community basing on their past experiences and disaster history of the community. In addition, it was found out that the barangay conducted communitybased seminars and workshops on disaster reduction and management process to identify communal hazards. The seminars and plan management initiated were attended by all community representatives and volunteers. The outputs from these community-based seminars and workshops are, then, channelled via general assembly among residents stressing that they should monitor disasters and prepare for it. Finally, the contingency plans were rehearsed and disseminated to the residents so that they will be well-informed in case of emergencies.

The result corresponds to the review that preparedness is a continuous cycle of planning, organizing, training, equipping, exercising, evaluation and improving activities to ensure effective coordination and the enhancement of capabilities to prevent, protect, mitigates the effects of natural disaster, acts of terrorism, and other man-made disaster (Kruger et.al., 2017). It is therefore considered that the sustainable development is the alternative mean to support the main resource of the community, from this approach solutions are provided to solve the environment problems (E.Lamberteb, 2017). Preparedness planning is essential to minimizing the impact of disasters on communities and individuals. It is a shared responsibility at the national, state, local community, and individual level (Das, 2018). Preparation, vulnerability and resilience are strongly linked concepts, as proper preparedness minimizes the consequences of the hazard and increases the ability of people to 
better cope and recover from the disruptive impacts of a hazard (Madzivhandila, 2018).

Meanwhile, there are many bottlenecks in disaster preparations (Foster, 2018). However, effective disaster response is not possible if measures are not taken before a disaster hit the community. It has been noticed that in Barangay San Miguel, their preparedness actions undertaken enable them to respond actively when disaster does strike. As extreme weather events are difficult to forecast under certain circumstances (K. Smith, 2003) residents in the flood and landslide prone areas need to prepare by having safety precautionary measures ready at all times, a mind-setting framework of the local chief executive of Barangay San Miguel. It has also been noted that disaster response operations in the community is centralized and the roles and responsibilities of the barangay/local officials are clear.

\section{Table 1: Level of Performance of BDRRMC in terms of Disaster Preparation}

\begin{tabular}{|l|c|c|c|c|c|c|c|}
\hline \multicolumn{1}{|c|}{ Items } & $\mathbf{5}$ & $\mathbf{4}$ & $\mathbf{3}$ & $\mathbf{2}$ & $\mathbf{1}$ & Mean & Description \\
\hline $\begin{array}{l}\text { 1. The BDRRMC prepared } \\
\text { contingency plans with local } \\
\text { risk map to update the } \\
\text { residents. }\end{array}$ & 253 & 43 & 2 & 0 & 0 & 4.48 & Excellent \\
\hline $\begin{array}{l}\text { 2. Contingency plans were } \\
\text { rehearsed and disseminated } \\
\text { for the residents to have idea } \\
\text { in case of emergencies. }\end{array}$ & 206 & 91 & 1 & 0 & 0 & 4.69 & Excellent \\
\hline $\begin{array}{l}\text { 3. Drills conducted to test } \\
\text { the contingency plan to find } \\
\text { out its effectiveness. }\end{array}$ & 228 & 68 & 2 & 0 & 0 & 4.76 & Excellent \\
\hline $\begin{array}{l}\text { 4. Disaster-related signage, } \\
\text { markers and directional } \\
\text { signs displayed in strategic } \\
\text { locations. }\end{array}$ & 215 & 80 & 3 & 0 & 0 & 4.71 & Excellent \\
\hline $\begin{array}{l}\text { 5. Established early warning } \\
\text { system to alarm the } \\
\text { residents in case of calamity. }\end{array}$ & 208 & 86 & 3 & 0 & 0 & 4.67 & Excellent \\
\hline \multicolumn{1}{c}{ Total (Ave) } & $\mathbf{2 2 2}$ & $\mathbf{7 3 . 6}$ & $\mathbf{2 . 2}$ & $\mathbf{0}$ & $\mathbf{0}$ & $\mathbf{4 . 7 3}$ & Excellent \\
\hline
\end{tabular}

Table 2 presents the level of performance of BDRRMC in terms of disaster mitigation. Statistical result indicated a total percentage of $4.66 \%$ with a descriptive equivalent of excellent, which means the performance is outstanding. This further manifests that the efforts initiated by BDRRMC of Barangay San Miguel through implementation of plans and projects is well-ordered which prevented the extreme effects of disaster in the community. Further, they identified the possible hazards and risks, and determined the potential disaster in the community as their basis in the implementation of hazard-resistant projects and safety standards. Initial safety measure was the rehabilitation of canals and warning systems that kept the residents updated and ready for the possible natural or man-made calamity in the locality. Building capacity to sufficiently respond to disaster requires commitment and understanding of potential hazards (Joerin, Steinberger, Krishnamurthy, \& Scolobig, 2018). Evidently, the local officials meaningfully engaged in disaster preparedness activities fitted to their community needs. 
To substantiate this result, residents also claimed that the community implements early warning systems through the installation of early warning devices in the identified hazard-prone areas. Well-coordinated communication system is also established. Handheld radios are available to areas with no telecom signals. Community officials and selected representatives conducted disaster trainings and cascaded awareness campaign to the residents through information disseminationrelated activities. They also have their own emergency response team for rescue composed of their own community leaders. These mitigation response practices are parallel to what was claimed (WorkeyeAsfaw, Nation, K.McGee, \& Christianson, 2018) that disaster management such as floodplain management should be developed and implemented based upon an integration of management resources and examine catchments and factors that influence behaviour and hazard in the local basis. This will result in avoiding (prevention) or in limiting (mitigation and preparedness) adverse impact of hazards, within the broad context of sustainable development (Rañesesa., 2018).

The countermeasures initiated by the barangay/local officials in Brgy. San Miguel evolved from defensive action to risk management efforts. Such efforts and initiatives resulted to living specifically with floods sustainably. Warned by the disasters that could arise, noting also that they have been exposed to several strategies and action plans due to benchmarking initiatives, the local officials were able to establish their own mitigation response framework to address their community needs.

\section{Table 2: Level of Performance of BDRRMC in terms of Mitigation Response}

\begin{tabular}{|l|c|c|c|c|c|c|c|}
\hline \multicolumn{1}{|c|}{ Item } & $\mathbf{5}$ & $\mathbf{4}$ & $\mathbf{3}$ & $\mathbf{2}$ & $\mathbf{1}$ & Mean & Description \\
\hline $\begin{array}{l}\text { 1. Identification of hazards and } \\
\text { risks and to determine the } \\
\text { potential calamity that may } \\
\text { occur. }\end{array}$ & 234 & 64 & 0 & 0 & 0 & $\mathbf{4 . 7 9}$ & Excellent \\
\hline $\begin{array}{l}\text { 2. Hazard resistant projects } \\
\text { were implemented in order to } \\
\text { lessen possible damages in the } \\
\text { locality. }\end{array}$ & 201 & 94 & 3 & 0 & 0 & $\mathbf{4 . 6 6}$ & Excellent \\
\hline $\begin{array}{l}\text { 3. Building resilience of } \\
\text { residents to disasters for them } \\
\text { to survive in case of catastrophic } \\
\text { events. }\end{array}$ & 165 & 124 & 8 & 0 & 0 & $\mathbf{4 . 5 1}$ & Excellent \\
\hline $\begin{array}{l}\text { 4. Implementation of safety } \\
\text { standards in order for the } \\
\text { residents to be always aware } \\
\text { and ready of any natural or } \\
\text { man-made calamity. }\end{array}$ & 202 & 91 & 4 & 1 & 0 & $\mathbf{4 . 6 6}$ & Excellent \\
\hline $\begin{array}{l}\text { 5. Information and warning } \\
\text { systems were implemented to } \\
\text { keep the residents updated on } \\
\text { the situation. }\end{array}$ & 212 & 83 & 3 & 0 & 0 & $\mathbf{4 . 7 0}$ & Excellent \\
\hline & $\mathbf{2 0 2 . 2}$ & $\mathbf{9 1 . 2}$ & $\mathbf{3 . 6}$ & $\mathbf{0 . 2}$ & $\mathbf{0}$ & $\mathbf{4 . 6 6}$ & Excellent \\
\hline
\end{tabular}

Table 3 illustrates the level of performance of BDRRMC in terms of disaster response. An excellent result is similarly obtained in this area. Statistical result showed a total percentage of $4.62 \%$ which has an excellent descriptive equivalent. The activation of contingency plans, execution of rescue and rehabilitation initiated by BDRRMC during 
the calamity is effectively implemented which restrained or averted the effects of the disaster in their locality. Accordingly, they mobilized volunteers for quick reactions and initiated appropriate operations that saved lives in the most affected areas. Further, immediate evacuations, food supplies, and medical assistance were provided that gradually restored the normal health condition of the affected residents.

A community officer stated that in support to disaster risk reduction, the community institutionalized Local Disaster Risk Reduction and Management Council. The community chief executive Hon. Harry C. Cabiling served as the head of the Emergency Operation Center. In addition, with the presence of Barangay Emergency Responder, the victims in an accident and other emergencies can be assisted immediately by the trained responders. This basic principle coincides with what has been propounded ( $P$. Ifeomallo, 2018) that the effectiveness of disaster response effort is heavily reliant upon the disaster responders themselves. Another significant factor for this outstanding implementation is the positive culture of the community. Pre-emptive evacuation policy is strictly implemented whenever disaster strikes. The residents automatically proceed to the evacuation center while the responders are immediately activated for search and rescue operations. There are available first aid and medical kits to emergency responders and health workers that take the responsibility for the needs and safety of the constituents during a disaster. As highlighted, the community has good sheltering strategy also due to the strategic identification of evacuation areas.

As emphasized by the chief executive, Barangay San Miguel remains steadfast in its commitment to increasingly heighten the awareness and preparedness in the community. Such that, this signifies their 'disaster preparedness' culture. This goes to show that having a disaster-ready community will definitely decrease fatalities and mitigate damages in case of disaster events (Thirawat \& Ponjan, 2014). Weaknesses in responding to disasters can increase the vulnerability of the people and cause damages (Curie, 2009).It is important to identify these weaknesses in order to improve the immediate response process which will ultimately minimize the loss of lives and damage to property, and will in turn enhance disaster response practices in the community. In other words, the barangay constituencies are proactive towards dealing with disaster specifically flooding because of their ability to cope using their own resources. It is worthy to note that there are many ways in which individuals can contribute to disaster response efforts specifically at the local level. This perceived initiative of the people in the barangay has developed their community-based adaptive strategies during disaster situations as attributed to the proactive leadership of the barangay officials.

The result runs counter to what has been popularly claimed that sustainable development effort addressing hazards does not yet appear to have penetrated to the institutional levels where disaster rersponse planning commonly takes place. The case of Barangay San Miguel is apparent that initiatives towards sustainable development pathways is their central component to ensure that disaster does not derail rural development. The community believes that strengthened information channels and exchanges within members of families and communities create human capital (Solecki, 2011) that is of equal importance to the availability of physical and financial capital especially during calamities. In this regard, the local officials believed that the participative capacity of the people in the community is the key category in the circle of disaster. The lower the participative capacity, the lower the resonance for 
development (DanielF.Lorenz, 2017), the lower prevention activities, and the lower the capacity to respond.

Another best practice as remarked by the residents, that BDRRMC integrated the differentiated needs of women into their emergency response operation plan. When distributing aid, mostly of the specific needs of the people are taken action by the local officials. Moreover, protecting women and their needs is an important component of disaster response and management. The agenda to protect women and their needs is definitely moving in Barangay San Miguel however, there is a need to provide gendersensitivity-training in disaster response teams and collecting more disaggregated data that their needs are addressed during disaster situations.

\section{Table 3: Level of Performance of BDRRMC in terms of Disaster Response}

\begin{tabular}{|l|c|c|c|c|c|c|c|}
\hline \multicolumn{1}{|c|}{ Item } & 5 & 4 & 3 & 2 & 1 & Mean & Description \\
\hline $\begin{array}{l}\text { 1. Mobilization of volunteers to } \\
\text { provide quick actions on the } \\
\text { eminent threats in the locality. }\end{array}$ & 245 & 49 & 2 & 0 & 0 & 4.79 & Excellent \\
\hline $\begin{array}{l}\text { 2. Search and rescue operations } \\
\text { in order to effect appropriate } \\
\text { actions to save life in the most } \\
\text { affected areas. }\end{array}$ & 214 & 79 & 3 & 0 & 0 & 4.68 & Excellent \\
\hline $\begin{array}{l}\text { 3. Evacuations of affected } \\
\text { populace purposely to relocate } \\
\text { and keep them safe. }\end{array}$ & 190 & 98 & 6 & 0 & 0 & 4.56 & Excellent \\
\hline $\begin{array}{l}\text { 4. Implementation of emergency } \\
\text { shelter for the affected residents } \\
\text { and to gradually return to normal } \\
\text { condition. }\end{array}$ & 150 & 125 & 21 & 0 & 0 & 4.41 & Excellent \\
\hline $\begin{array}{l}\text { 5. Medical operations to provide } \\
\text { immediate attention to restore } \\
\text { normal health condition of the } \\
\text { affected residents. }\end{array}$ & 204 & 90 & 1 & 1 & 0 & 4.65 & Excellent \\
\hline \multicolumn{1}{|c|}{ Total (Ave.) } & 200.6 & 88.2 & 6.6 & 0.2 & 0 & 4.62 & Excellent \\
\hline
\end{tabular}

Table 4 illustrates the level of performance of BDRRMC in terms of disaster recovery. The statistical result indicated a total percentage of 4.56 with a descriptive equivalent of excellent which means that the performance is outstanding. The result is exhibited by post-disaster projects and services initiated by the BDRRMC and the local government which restricted extreme effects of the disaster in their community. They implemented rehabilitation for the damaged infrastructures, and housing and health care facilities were restored as noticed by the constituents.

Further, the distribution of relief goods was conducted for the affected residents. Conducting workshops on livelihood projects such as making chorizo, provision of free seedlings for the farmers and giving of food cart to those who wanted to start a small business were organized to uplift the economic condition and sustain the basic needs of the residents as experienced by the residents when flooding and landslides hit considering that the community has several flood-hazard areas. One strong point of the community is the active leadership of their community chief executive, Hon. Cabiling as claimed by many residents. BDRRMC established strong partnerships with the provincial and municipal government, national agencies of the government, 
NGOs and civil society organizations on top of the spirit of volunteerism among residents. Such post-disaster actions of the local government demonstrate a certain level of quality of disaster response at the local level. It further relates to the study that disaster management aims to assure prompt and appropriate assistance to victims of disaster and achieve rapid and effective recovery (Bowen, 2018).

The experience of individuals, families and communities affected by disaster is indicative of how various interventions help or do not help affected communities to recover from the adverse effects (Reinmar,S. 2018). Barangay San Miguel in this regard was able to consistently show high values over time and disaster-related issues appeared to have been effectively addressed. The ability of the local authorities to lead and communicate during the recovery process was high. People were satisfied of the recovery process because they felt that they were integrated in the planning and shaping of their affected community. Their community always believe that flexible approaches are needed to ensure communities and authorities interact effectively with each other in the recovery process.

\section{Table 4: Level of Performance of BDRRMC in terms of Disaster Recovery}

\begin{tabular}{|c|c|c|c|c|c|c|c|}
\hline Items & 5 & 4 & $\mathbf{3}$ & 2 & 1 & $\begin{array}{c}\text { Mea } \\
\mathbf{n}\end{array}$ & Description \\
\hline $\begin{array}{l}\text { 1. Distribution of relief } \\
\text { goods services to the } \\
\text { affected residents for them } \\
\text { to continue living in a } \\
\text { normal life. }\end{array}$ & 253 & 43 & 1 & 0 & o & 4.83 & Exceellent \\
\hline $\begin{array}{l}\text { 2. Relocation and health } \\
\text { care projects for the } \\
\text { residents to attain and } \\
\text { improve their well-being. }\end{array}$ & 206 & 86 & 5 & o & o & 4.66 & Exceellent \\
\hline $\begin{array}{l}\text { 3. Infrastructure and } \\
\text { rehabilitation projects to } \\
\text { restore normal economic } \\
\text { flow of the residents and } \\
\text { the whole community. }\end{array}$ & 173 & 116 & 5 & o & o & 4.51 & Excellent \\
\hline $\begin{array}{l}\text { 4. Price control monitoring } \\
\text { to pre-empt hoarding of } \\
\text { prime commodities in the } \\
\text { market. }\end{array}$ & 123 & 109 & 59 & 6 & o & 4.16 & Very good \\
\hline $\begin{array}{l}\text { 5. Livelihood projects for } \\
\text { affected populace to uplift } \\
\text { economic condition and } \\
\text { sustain their basic needs. }\end{array}$ & 197 & 96 & 4 & o & o & 4.63 & Excelllent \\
\hline Total (Ave.) & 190.4 & 90 & 14.8 & 1.2 & $\mathbf{O}$ & 4.56 & Excellent \\
\hline
\end{tabular}

\section{Conclusions and Recommendations}

In view of the findings, it has been found out that majority of the sampled population substantiated that there is an excellent delivery in the implementation of the programs relative to disaster risk reduction at the local level in Barangay San Miguel, Compostela, Compostela Valley. When the community received the award as Best Implementer in 2015, the result of this study supplements such outstanding performance in terms of disaster preparation, mitigation, response and recovery at the local level. Such extraordinary performance was manifested by the lived experiences of the people in the community that they were able to contain when disaster hit them. 
The efforts initiated by BDRRMC of Barangay San Miguel in the implementation of plans and projects that controlled and prevented the extreme effects of the calamity that took place were effective. The activation of contingency plans, execution of rescue and rehabilitations initiated by BDRRMC were effective as demonstrated by the residents who understand the potential dangers that these events may bring. The post-disaster projects and services initiated by the BDRRMC was a significant factor that restricted extreme effects among community people notwithstanding the able leadership of their community chief executive. To this regard, the barangay government was certain that they properly designed and implemented their BDDRMC plans and have completely used their plans. In the implementation of their disaster protocols, the community experienced no troubles due to the cooperation of the people which exhibits their resilience and preparation. Further, their experience from Typhoon Bopha in 2012 has made them better prepared.

Given the highlights of the findings and the limitation of the study, recommendations are advanced for future considerations. The local government should sustain the "disaster preparedness" culture of the community through strict, consistent and regular monitoring in the implementation of their disaster risk reduction and management plans and initiate more disaster preparedness contingency plans and measures. The result of the study provides practical implications for policymakers and government officials to craft disaster risk reduction interventions based on the feltneeds and vulnerability conditions of the community. This is essential to reduce the hazard exposure and sensitivity, and for enhancing the adaptive capacity.

\section{References}

A. M. ADEWALE, "The effects of parental socio-economic status on academic performance of students in selected schools in Edu Lga of Kwara State Nigeria.," International journal of academic research in Business and social sciences, p. 230, 2012.

H. BOWEN, BOWEN, H. (2018). Investment in learning: The individual and social value of American higher education., Routledge., 2018. https://doi.org/10.4324/9781351309929

A. J. ORR, ORR, AMY J. "Black-white differences in achievement: The importance of wealth." Sociology of education (2003): 281-304., 2003.

J. CURRIE, "Healthy, Wealthy, and Wise: Socioeconomic Status, Poor Health in Childhood, and Human Capital Development," Journal of Economic Literature, vol. 47, no. 1, pp. 87-122, 2009. https://doi.org/10.1257/jel.47.1.87

D.-K. P.E., "The influence of parent education and family income on child achievement: the indirect role of parental expectations and the home environment," Journal of Family Psychology, vol. 19, no. 2, p. 294, 2005. https://doi.org/10.1037/0893-3200.19.2.294

J. B. \&. M. LEWIS, "The Increasing Significance of Class: The Relative Effects of Race and Socioeconomic Status on Academic Achievement," Journal of Poverty, vol. 6, no. 2, pp. 21-35, 2002. https://doi.org/10.1300/J134v06n02_02

M. C. R. S. D. U. L.-L. A. L. \&. A. M. Dilley, "Natural Disaster Hotspots: a Global Risk analysis," The World Bank, 2005.

T. \&. V. A. M. Mitchell, "Convergence of Disaster Risk Reduction and Climate Change Adaptation," UK Department for International Development (DFID), 2008. 
K. SMITH, Environmental Hazards: Assessing Risk and Reducing Disaster,, Routledge, 2003.

L. MATUNHAY, "Disaster Management: Towards Building Community Resilience," International Journal of Scientific Research and Management, vol. 6, no. 12, pp. 353-366, 2018.

B. \&. D. L. R. MALAYANG III, "Practical Data For Barangay-Oriented Resources And Climate Change Vulnerability," 2013.

M. A. E.LAMBERTEB, International Journal of Disaster Risk Reduction, vol. 24, pp. 91-99, 2017. https://doi.org/10.1016/j.jijrr.2017.06.002

R. W. P. M. K. LINDELL, "Preparedness for Emergency Response: Guidelines for the Emergency Planning Process," Disasters, vol. 27, no. 4, pp. 336-350, 2003. https://doi.org/10.1111/j.03613666.2003.00237.x

" SOLECKI, W., LEICHENKO, R., \& O'BRIEN, K. (2011). Climate change adaptation strategies and disaster risk reduction in cities: connections, contentions, and synergies. Current Opinion in Environmental Sustainability, 3(3), 135-141.". https://doi.org/10.1016/j.cosust.2011.03.001

W. L. R. \&. O. K. SOLECKI, "SOLECKI, W., LEICHENKO, R., \& O'BRIEN, K. (2011). Climate change adaptation strategies and disaster risk reduction in cities: connections, contentions, and synergies. Current Opinion in Environmental Sustainability, 3(3), 135-141.," Currfent Opinion in Environmental Sustainability, vol. 3, no. 3, pp. 135-141, 2011. https://doi.org/10.1016/j.cosust.2011.03.001

LOCAL GOVERMENT CODE OF 1991 (Republic Act 7160), Republic of the Philippines.

"HYOGO FRAMEWORK FOR ACTION 2005-2015: Building the resilience of nations and communities to disasters," United Nations Office for Disaster Risk Reduction, Japan, 2005.

N. CHAISATIT, V. R. M. HERNÁNDEZ, J. O. S. RODRÍGUEZ AND M. A. S. CAMPOS, "Sustainability assessment system of natural resource management for tourism in the community of San Pedro Atlapulco, the State of Mexico, Mexico," International Journal of Business and Management, vol. II, no. 4, pp. 1-21, 2014.

\section{P. A. *. JUDY KRUGER, C. F. H. P. M. LISA BUNDARA SINCLAIR AND P. AND BRENDA} SILVERMAN, "Enhancing individual and community disaster preparedness: Individuals with disabilities and others with access and functional needs," Disability and Health Journal, vol. 11, pp. 170-173, 2017.

M. K. RAÑESESA, A. CHANG-RICHARDS, J. RICHARDSB AND A. J. BUBBC, "Measuring the Level of Disaster Preparedness in Auckland," Procedia Engineering, 2018.

H. WORKEYEASFAW, S. L. F. NATION, T. K.MCGEE AND A. A. C. CHRISTIANSON, "Evacuation preparedness and the challenges of emergency evacuation in Indigenous communities in Canada: The case of Sandy Lake First Nation, Northern Ontario," International Journal of Disaster Risk Reduction, 2018.

N. THIRAWAT and A. P. PONJAN, "Thailand's Flood Management Policy: Issues, Developments And Implications For The Thai Tourism Industry," in 11th International Academic Conference, Reykjavik, Bangkok, Thailand, 2014.

T. S. MADZIVHANDILA, "Disaster Management In South Africa: The Irony Of Fire Fighting Approach Towards Natural Hazards," in 39th International Academic Conference, Amsterdam, Amsterdam, 2018. 
N. A. W. a. L. Foster, "Improving disaster response through the science of work," International Journal of Disaster Risk Reduction, vol. 31, pp. 112-120, 2018. https://doi.org/10.1016/j.ijdrr.2018.04.026

REINMAR, S. ET. AL.., "Progress on integrating climate change adaptation and disaster risk reduction for sustainable development pathways in South Asia: Evidence from six research projects," International Journal of Disaster Risk Reduction, vol. 31, pp. 92-101, 2018. https://doi.org/10.1016/j.ijdrr.2018.04.023

R. DAS, "Disaster preparedness for better response: Logistics perspectives," International Journal of Disaster Risk Reduction, vol. 31, pp. 156-159, 2018.

P. IFEOMAILO, R. IZUAGBE, A. J.C.MOLE AND A. L. EKWUEME, "Measuring disaster preparedness and response practices in university libraries in Nigeria: The role of disaster equipment," International Jopurnal of Disaster Risk Reduction, vol. 31, pp. 85-91, 2018. https://doi.org/10.1016/j.ijdrr.2018.04.007

S. HETTIGE AND R. H. A. D. AMARATUNGA, "Community level indicators of long term disaster recovery," in Procedia Engineering.

S. HETTIGE, R. HAIGH AND A. D. AMARATUNGA, "Community level indicators of long term disaster recovery," in Proceedia Engineering, 2017.

L. M. MATUNHAY, "Disaster Preparedness and Resiliency of the Local Government Unit of Compostela," International Journal of Sciences; Basic and Applied, vol. 42, no. 3, pp. 56-67, 2018.

J. JOERIN, F. STEINBERGER, R. R. KRISHNAMURTHY AND A. A. SCOLOBIG, "Disaster recovery processes: Analysing the interplay between communities and authorities in Chennai, India," in Procedia Engineering, 2018.

W. H. E. AL., "Climate change and natural disasters: Government mitigation activities and public property demand response," Land Use Policy, vol. 82, pp. 436-443, 2019. https://doi.org/10.1016/j.landusepol.2018.12.026

HAJERAL-DAHASH, U. KULATUNGA AND A. MENAHATHAYAPARAN, "Weaknesses during the disaster response management resulting from war operations and terrorism in Iraq," International Journal of disaster Risk Reduction, 2018. 